\title{
OPEN A new method based on diffusive gradients in thin films for in situ monitoring microcystin-LR in waters
}

\author{
LeiYao ${ }^{1,2}$, Alan D. Steinman ${ }^{3}$, Xiang Wan ${ }^{1,2}$, Xiubo Shu ${ }^{4} \&$ Liqiang Xie ${ }^{1 *}$ \\ The passive sampling method of diffusive gradients in thin-films (DGT) was developed to provide a \\ quantitative and time-integrated measurement of microcystin-LR (MC-LR) in waters. The DGT method \\ in this study used HLB (hydrophilic-lipophilic-balanced) material as a binding agent, and methanol \\ as an eluent. The diffusion coefficient of MC-LR was $5.01 \times 10^{-6} \mathrm{~cm}^{2} \mathrm{~s}^{-1}$ at $25^{\circ} \mathrm{C}$ in $0.45 \mathrm{~mm}$ thick \\ diffusion layer. This DGT method had a binding capacity of $4.24 \mu \mathrm{g}$ per binding gel disk $\left(3.14 \mathrm{~cm}^{2}\right)$, \\ ensuring sufficient capacity to measure MC-LR in most water matrices. The detection limit of HLB \\ DGT was $0.48 \mathrm{ng} \mathrm{L}^{-1}$. DGT coupled to analysis by HPLC appears to be an accurate method for MC-LR \\ monitoring. Comparison of DGT measurements for MC-LR in water and a conventional active sampling \\ method showed little difference. This study demonstrates that HLB-based DGT is a useful tool for in situ \\ monitoring of MC-LR in fresh waters.
}

As cyanobacteria (blue-green algae) grow in eutrophic waters, various toxins can be excreted from live or dead cells $^{1,2}$. One category of toxins is microcystins (MCs), a hepatotoxin containing cyclicheptapeptides ${ }^{3}$, which can be released from several species of cyanobacteria. Microcystin-LR (MC-LR) is the one of most harmful among the 100 or more microcystin congeners ${ }^{1}$, and is also the most frequently reported $\mathrm{MC}^{4}$. The maximum allowable concentration (MAC) for MC-LR in drinking water was established as $1 \mu \mathrm{g} \mathrm{L}^{-15}$. Reported concentrations of MC-LR in Taihu Lake (China) range from $0.05-3.38 \mu \mathrm{g} \mathrm{L}^{-16-9}$. MC-LR has wide-ranging negative impacts on organisms, including humans ${ }^{3,10-12}$. A Tolerable Daily Intake (TDI) value of $0.04 \mu \mathrm{g} \mathrm{kg}^{-1} \mathrm{MC}$-LRof body weight per day was proposed as a provisional guideline by the WHO (World Health Organization) ${ }^{13}$. Therefore, precise monitoring is essential to understand MC fate and behavior, and to provide data to assess possible risks to human health and ecosystems.

Inactive sampling methods, where water or sediment samples are collected on site and transferred to the lab for detection and measurement of concentration, is a common procedure for many organic chemicals, such as BPs (bisphenolA) ${ }^{14}$, PCBs (polychlorinated biphenyls) ${ }^{15}$, and $\mathrm{MCs}^{4}$. An active sampling approach provides a concentration at a discrete time, but also usually involves a large investment of time and cost. In contrast, passive sampling methods have been developed in recent decades, and partly through in situ deployment ${ }^{16}$ (Gong et al., 2018), can overcome active sampling shortcomings, such as less pretreatment of samples, higher resolution than active sampling methods, and lower requirements of experimental skills. Passive sampling methods are complementary to direct sampling of water and biological samples. Dominant passive sampling approaches include the Polar Organic Chemical Integrative Sampler (POCIS) ${ }^{17}$, Chemcatcher ${ }^{18}$, Solid Phase Adsorption Toxin Tracking $(\text { SPATT })^{19}$, and Diffusive Gradients in Thin films (DGT) $)^{20}$. Both POCIS and SPATT have been deployed successfully to detect or monitor microcystins ${ }^{21-23}$, providing a robust way to monitor microcystin concentrations. But according to a previous report ${ }^{24}$, under some conditions, POCIS may result in inaccurate estimations of organic compound concentrations. SPATT also presents some limitations, such as a lack of calibration (no optimal deployment time), thereby limiting the more widespread adoption of this technology for monitoringof

\footnotetext{
${ }^{1}$ State Key Laboratory of Lake Science and Environment, Nanjing Institute of Geography and Limnology, Chinese Academy of Sciences, Nanjing, 210008, China. ${ }^{2}$ College of Resources and Environment, University of Chinese Academy of Sciences, Beijing, 100049, China. ${ }^{3}$ Annis Water Resources Institute, Grand Valley State University, 740 West Shoreline Drive, Muskegon, MI, 49441, USA. ${ }^{4}$ College of Resources and Environment Engineering, Guizhou University, Guiyang, 550025, China. *email: Iqxie@niglas.ac.cn
} 


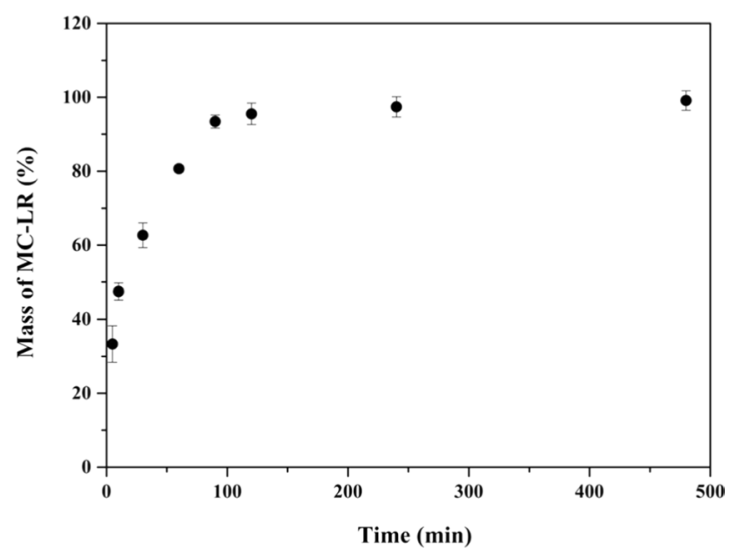

Figure 1. The mass of MC-LR adsorbed by binding gel in $20 \mathrm{~mL}$ solutions containing $200 \mu \mathrm{gL}^{-1} \mathrm{MC}-\mathrm{LR}$ and $0.01 \mathrm{M} \mathrm{NaCl}$. The $\mathrm{Y}$ axis refers to the ratio of mass of MC-LR adsorbed by the HLB gel divided by the mass contained in the initial solutions. Error bars are calculated from the standard deviation of the replicates $(\mathrm{n}=3)$.

pollutants ${ }^{25}$. The DGT technology was developed by Davison and Zhang ${ }^{26}$ and initially was used to detect trace metals in natural fresh water systems ${ }^{20}$.

Recently, Chen et al. ${ }^{27,28}$ and Zheng et al..$^{29}$ have successfully used this technology to measure antibiotics and BPAs in waters. Chen et al. ${ }^{30}$ used HLB (hydrophilic-lipophilic-balanced, OASIS) as the binding layer in DGT to measure HPCPS (house-hold and personal care products) in waters. Zou et al. ${ }^{31}$ also used HLB in DGT to detect organo-phosphorus flame retardants. The HLB material is a well-known and effective adsorbing material for several organics, including $\mathrm{MCs}^{32}$.

In the present study, we prepared the binding gel with HLB incorporated into agarose gel. In assessing the performance characteristics of the new DGT device for detecting extracellular MC-LR, we studied the binding kinetics, elution efficiency using four different eluents, capacity of the binding gels, and the possible influence of lake water $\mathrm{pH}$ and ionic strength. The DGT devices employing HLB gels were tested in natural waters, and the resulting concentrations were compared with conventional active sampling.

\section{Results and Discussion}

Adsorption by experimental devices. All materials used in the experiment should be non-adsorptive and non-reactive with respect to MC-LR. Hence, the diffusive gels, DGT models, filter membranes, and polypropylene pipes (as an efferent vessel for the extraction process) were assessed for their possible adsorption of MC-LR. The results of the adsorption tests indicated that there was a limited adsorption ratio by the DGT models $(0.26 \%)$, polypropylene pipes $(0.22 \%)$, diffusive gels $(0.43 \%)$, and PTFE filter membranes $(0.23 \%)$. These results suggest that the four materials can be used without worry of adsorption by materials used in the experiments.

Sorption kinetics of MC-LR. The uptake of MC-LR by the binding gel increased quickly during the first $60 \mathrm{~min}$, and then reached a plateau by approximately $90 \mathrm{~min}$, when more than $95 \%$ of the MC-LR had been adsorbed (Fig. 1). The average binding rate calculated from the DGT unitwas $0.59 \mathrm{ng} \mathrm{cm}^{-2} \mathrm{~min}^{-1}$ when they were deployed in $200 \mathrm{\mu g} \mathrm{L}^{-1}$ of MC-LR at $25^{\circ} \mathrm{C}$. The average binding rate of the binding gel during the first $30 \mathrm{~min}$ was $3.09 \mathrm{ng} \mathrm{cm}^{-2} \mathrm{~min}^{-1}$, which was sufficient to ensure uptake by the DGT. Similar results were reported by Zheng et al. ${ }^{29}$ using activated charcoal binding gels for measuring BPs. The adsorption rate discrepancy between DGT device and binding gel suggests that MC-LR binds onto the gels in DGT with sufficient speed to ensure that the concentration of MC-LR at the diffusive gel/binding gel interface is almost zero, validating the use of Eq. (1).

Elution efficiencies of MC-LR. Stable and high elution efficiency of MC-LR from HLB gels was needed to calculate $C_{\mathrm{DGT}}$. In the present study, four kinds of eluents were tested to identify the most suitable one. Eluent $\mathrm{A}$, consisting of $10 \mathrm{~mL}$ of methanol only, had the highest elution efficiency (83.09 $\pm 4.2 \%)$ (Fig. 2). The other three eluents had lower efficiencies, ranging from $56.9 \pm 3.58 \%$ to $66.1 \pm 2.42 \%$.

Diffusion coefficient. The effective diffusion coefficient of MC-LR was determined by the DGT time-series deployment method. This method is more widely used for the calculation of the diffusion coefficient than the diffusion cell method because it more closely reflects natural conditions ${ }^{33}$. The accumulated mass of MC-LR was linearly correlated with the deployment time of DGT units. The slope fitting equation was used to calculate the effective diffusion coefficient according to Eq. 3. The diffusion coefficient of MC-LR was $5.00 \times 10^{-6} \mathrm{~cm}^{2} \mathrm{~s}^{-1}$, at $25^{\circ} \mathrm{C}$ in the $0.45 \mathrm{~mm}$ thickness diffusion layer. This was similar to the diffusion coefficient of BPA (slightly higher than BPB, lower than BPF) measured using an agarose diffusive gel reported by Zheng et al. ${ }^{29}$. A prior study showed the diffusive coefficient of several HPCPs ranged from $3.36 \times 10^{-6}-7.30 \times 10^{-6} \mathrm{~cm}^{2} \mathrm{~s}^{-1}$ at $25^{\circ} \mathrm{C}$ using the agarose diffusive gel ${ }^{30}$.

DGT blanks and detection limits. DGT blank concentrations were evaluated by measuring the mass of MC-LR, using HPLC, in HLB gels retrieved from DGT units that were deployed in $0.01 \mathrm{M} \mathrm{NaCl}$ solution for $24 \mathrm{~h}$. 


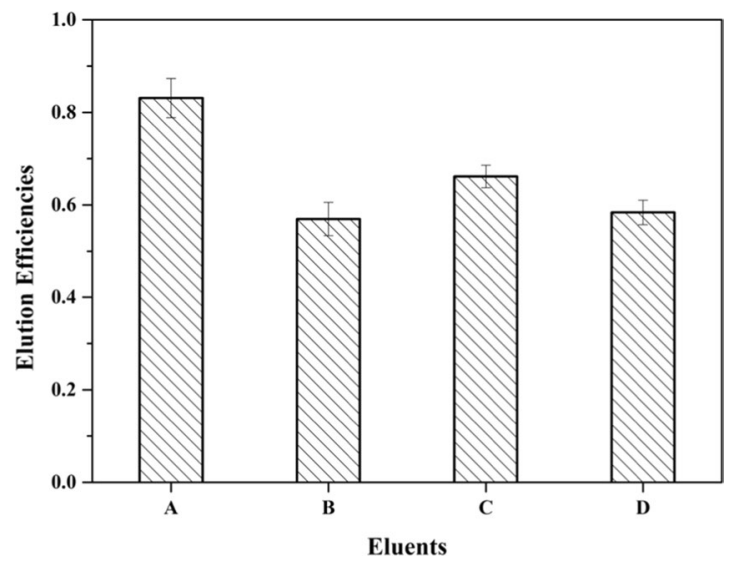

Figure 2. Elution Efficiencies (\%) of MC-LR from Binding Gels Eluted by Different Eluents (A:10 mL of methanol; $\mathrm{B}: 7 \mathrm{~mL}$ of methanol $+3 \mathrm{~mL}$ of $1 \mathrm{M} \mathrm{NaOH}$; $\mathrm{C}: 9 \mathrm{~mL}$ of methanol $+1 \mathrm{~mL}$ of $1 \mathrm{M} \mathrm{NaOH} ; \mathrm{D}: 7 \mathrm{~mL}$ of methanol $+3 \mathrm{~mL}$ of $1 \mathrm{M} \mathrm{HCl}$, Error bars are calculated from the standard deviation of the replicates $(\mathrm{n}=3)$.

No MC-LR was detected. A method detection limit (MDL) for HLB DGT of $0.48 \mathrm{ng} \mathrm{L}{ }^{-1}$ was calculated assuming a deployment time of $96 \mathrm{~h}$ at $25^{\circ} \mathrm{C}$ with a $0.45 \mathrm{~mm}$ thick diffusive gel. The reported concentrations of MC-LR were $0.05-2 \mu \mathrm{g} \mathrm{L}^{-1}$ in Taihu Lake. Given the much lower values of the MDL than the reported natural concentrations, DGT coupled to analysis by HPLC appears to have adequate sensitivity for water quality monitoring. A longer deployment time could be used to enhance the adsorbed mass and lower the MDL proportionately if the concentration of MC-LR was lower than the $\mathrm{MDL}^{34}$.

Effects of $\mathrm{pH}$ and ionic strength. According to Kim et al. $.^{35}, \mathrm{pH}$ has a considerable impact on MC-LR adsorption when the compound contains many carboxyl, phosphonate groups, and amine groups, but has little effect on neutral compounds ${ }^{36}$. The performance of the HLB DGT for measuring MC-LR in solutions with various $\mathrm{pH}$ and ionic strength (IS) conditions is shown in Fig. 3. A pH range from 5 to 8 had no obvious effect on the measurement of MC-LR by DGT. This suggests that DGT performance is generally independent of solution $\mathrm{pH}$ within this range and hence, DGT can be directly used for MC-LR measurement in field conditions that have a $\mathrm{pH}$ of 5-8.

There was no observed effect of the different IS on MC-LR (Fig. 3) adsorption experiment. IS could potentially affect the adsorption process of several organics, such as sulfachloropyridazine, tylosin, and oxytetracycline ${ }^{37}$, but has no discernible effect on materials without significantly ionized forms $\mathrm{s}^{38,39}$. The result that IS has little effect on adsorption is consistent with previousstudies ${ }^{36}$. Measurement of BPs using DGT with activated charcoal binding gel also was unaffected at an IS of 0.001-0.05 $\mathrm{M}^{29}$. While the DGT with XAD18 (styrene divinylbenzene copolymer) binding gel to detect the antibiotic sulfamethoxazole was unaffected at IS from $0.001-0.01 \mathrm{M}$, it was affected at a concentration of $0.05 \mathrm{M}^{28}$. These findings indicate that the DGT unit with HLB binding gel for measuring MC-LR is suitable in freshwater, and some work has been done by Xie et al. ${ }^{40}$ in seawater, still further work is needed on the effect of IS before DGT is applied in different matrices.

Capacity for DGT response. To ensure an accurate measurement by DGT when they are deployed at high concentrations or over the long-term, the binding phase must have sufficient capacity to avoid saturation. The mass of MC-LR adsorbed on the HLB gel within the DGT units increased linearly from $0-24 \mathrm{~h}$ and was close to the theoretical 1:1 line (Fig. 4). The adsorption capacity of DGT with HLB binding gel for MC-LR was $1.35 \mu \mathrm{g} \mathrm{cm}^{-2}$. Based on this capacity, if deployed for 2 weeks, the maximum concentration which could be retained would be $10 \mu \mathrm{g} \mathrm{L}^{-1}$; if deployed for 1 month, the maximum concentration would be $4.6 \mu \mathrm{gL}^{-1}$. However, much shorter deployment times would likely be used to avoid the possibility of biofouling or other disturbances in the environment. In most situations, MC-LR concentrations in polluted waters would be less than $10 \mu \mathrm{L} \mathrm{L}^{-1}$, so the capacity of DGT devices equipped with HLB binding gel is therefore more than adequate for monitoring MC-LR in most natural environments.

Testing in natural waters. In this study, the thickness of DBL (Diffusive Binding Layer, $\delta$ ) is not negligible,

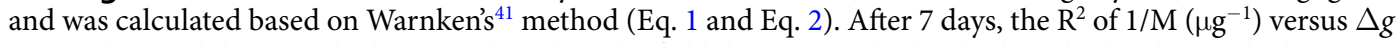
$(\mathrm{mm})$ plots and the DBL thickness $(\delta)$ based on the field data were calculated. The calculated DBL thickness $(\delta)$ was $0.21 \mathrm{~mm}$.

$$
\begin{aligned}
\partial & =\frac{b}{m}\left(\frac{D_{w}}{D_{g e l}}\right) \\
C_{D G T} & =\left(1 / m D_{g e l} A t\right)
\end{aligned}
$$



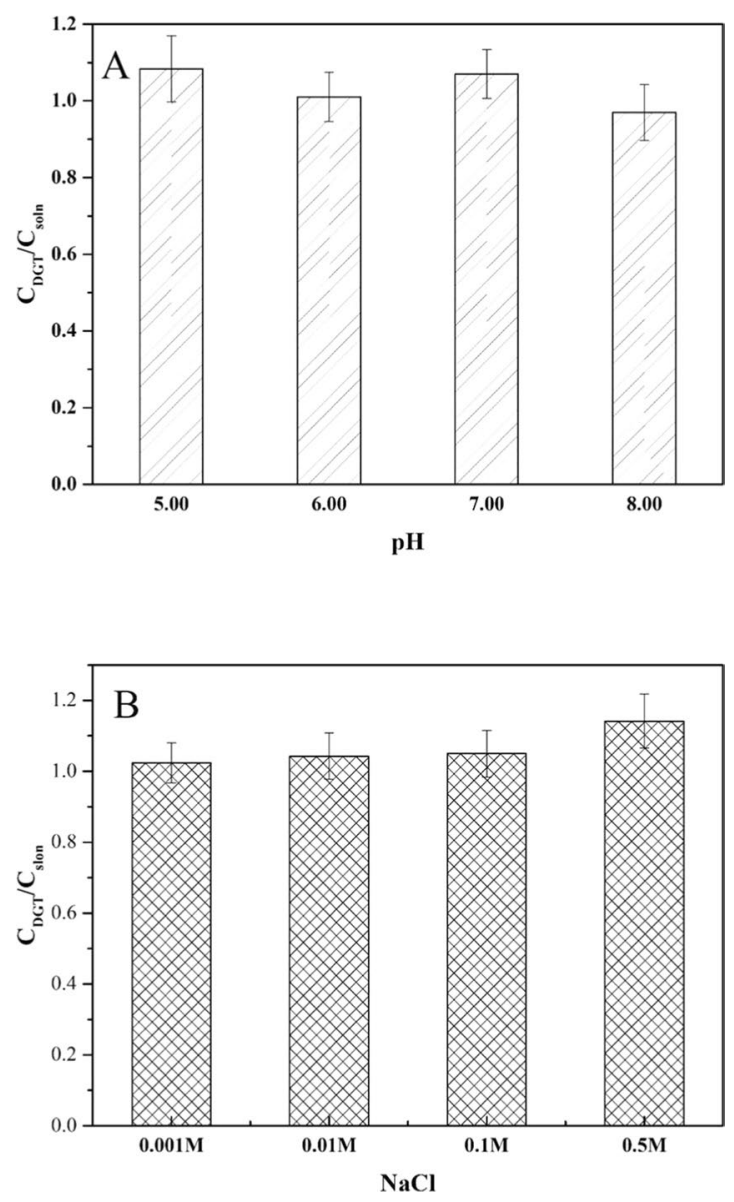

Figure 3. Effect of $\mathrm{pH}(\mathbf{A})$ and ionic strength $(\mathbf{B})$ on the ratio of DGT-measured concentrations $\left(C_{\mathrm{DGT}}\right)$ to their concentrations in bulk solutions $\left(C_{\text {soln }}\right)$ (there were no statistically significant differences among the $\mathrm{pH}$ and IS treatment levels in each panel), error bars are calculated from the standard deviation of the replicates $(n=3)$.

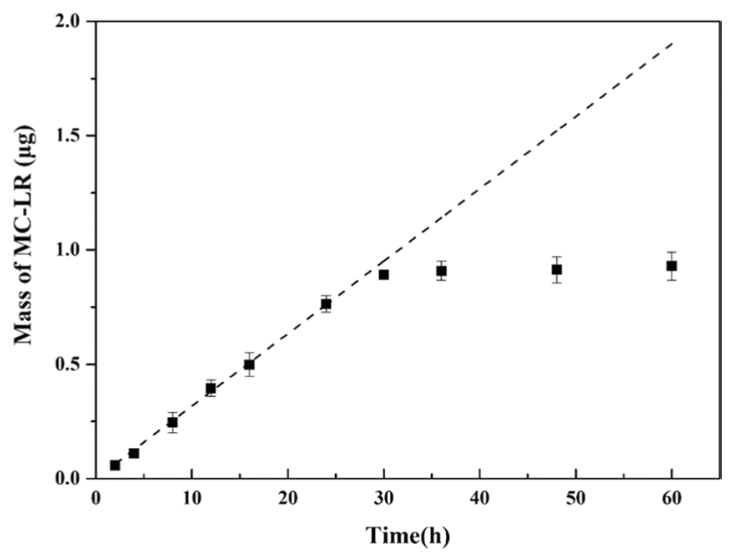

Figure 4. Measured masses of MC-LR adsorbed onto the HLB gels in DGT units deployed in well-stirred solutions for different times with an MC-LR concentration $=200 \mu \mathrm{gL}^{-1}$. The dashed line is predicted from the known solution concentrations using Eq. (1), error bars are calculated from the standard deviation of the replicates $(n=3)$.

The DGT units were deployed in Taihu Lake (Meiliang Bay). The concentrations of MC-LR detected by active sampling were $0.276-0.311 \mu \mathrm{g} \mathrm{L}^{-1}$ over the four days, while the result of the passive DGT method was $0.294 \mu \mathrm{g} \mathrm{L}^{-1}$. This MC-LR concentration is similar to those reported for other systems, including Meiliang Bay in Taihu Lake ${ }^{4}$ and Oneida Lake ${ }^{42}$, which were both measured with the active sampling method. The MC-LR 


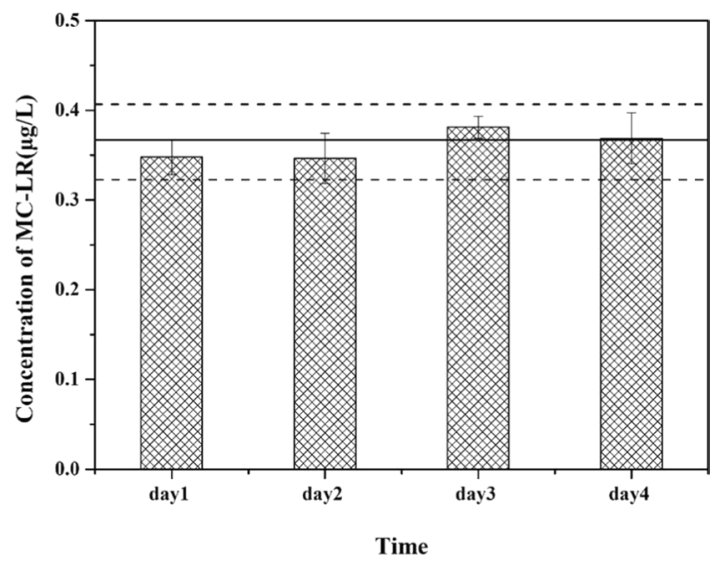

Figure 5. The concentrations of MC-LR during a 4 day sampling period. The solid line is the time-averaged concentrations of MC-LR detected by DGT. The dotted lines represent the maximum and minimum concentrations of MC-LR detected by DGT. The bar graph represents the concentrations of MC-LR detected by the active sampling method, error bars are calculated from the standard deviation of the replicates $(n=3)$.

concentrations obtained through the passive sample method generally fell within the minimum and maximum concentrations detected by the active method (Fig. 5), suggesting that the DGT with HLB binding gel is an appropriate tool for detecting MC-LR in natural waters.

\section{Methods}

Materials and reagents. The DGT detection result, $C_{\mathrm{DGT}}$, provides a dynamic concentration of organic materials in the solution using Fick's first law of diffusion ${ }^{26}$ :

$$
C_{D G T}=\frac{M(\Delta g+\delta)}{D A t}
$$

Where $M(\mu \mathrm{g})$ represents the measured mass of a target material adsorbed on the binding gel, $\Delta g(\mathrm{~mm})$ is the thickness of the diffusion layer, $\delta(\mathrm{mm})$ is the DBL thickness, $D\left(\mu \mathrm{g} \mathrm{cm}^{-2} \mathrm{~s}^{-1}\right)$ is the diffusion coefficient of the target material, $A\left(\mathrm{~cm}^{2}\right)$ represents the area of the DGT device exposed to the aquatic matrix, and $t(\mathrm{~s})$ represents the time that the DGT device was deployed in the aquatic matrix.

The DGT moldings of ABS (acetonitrile-butadiene-styrene) were obtained from DGT Research Ltd., United Kingdom. The self-made holders (cylindrical, $2 \mathrm{~L}, 30 \mathrm{~cm}$ high) for deployment of DGT devices were made of polytetrafluoroethylene (PTFE). Stock solutions (in water) of MC-LR (Taiwan Algal Science Inc.) were prepared at $50 \mathrm{mg} \mathrm{L}^{-1}$ and stored at $4{ }^{\circ} \mathrm{C}$. Methanol (HPLC grade) was purchased from Merck China. HLB was purchased from Waters Oasis, USA. The PTFE filter membrane (diameter $25 \mathrm{~mm}$, pore size $0.45 \mu \mathrm{m}$, thickness $150 \mu \mathrm{m}$ ) was purchased from Shanghai Anpel Scientific Instrument Co. The polypropylene (PP) pipes (Corning, USA) were used to extract the MC-LR from binding gel into the methanol. Ultrapure water (Thermo Scientific) was used during the whole experiment.

Chemical analysis. Quantification of MCs was performed on an Agilent 1000 series high performance liquid chromatography (HPLC) system with a DAD detector (Agilent, Palo Alto, CA, USA) according to the method of Su et al. (2015). Briefly, MCs were extracted by using HLB cartridges and measured by HPLC. The HLB cartridges were previously activated. The samples (filtered before) were then applied at a flow rate of $1 \mathrm{~mL} \mathrm{~min}^{-1}$, with a further washing step with $5 \%(\mathrm{v} / \mathrm{v})$ methanol, and a final elution with methanol was performed. A volume of $15 \mathrm{~mL}$ was used for the washing step and $10 \mathrm{~mL}$ for the elution step described above. Finally, the eluent was dried under $\mathrm{N}_{2}$ gas at $40^{\circ} \mathrm{C}$ prior to reconstitution in $1.0 \mathrm{~mL}$ of methanol. A $500 \mu \mathrm{L}$ sample was prepared for HPLC analysis. The extracted solution of DGT units was injected into the HPLC without pre-concentration.

Evaluation of possible adsorption. DGT moldings, diffusive gels, PTFE filter membranes, and PP pipes were soaked in $200 \mathrm{~mL}$ of $200 \mu \mathrm{g} \mathrm{L}^{-1} \mathrm{MC}$-LR solutions and then placed on a shaking table for 24 hours at 200 cycles per minute at room temperature. The concentrations of MC-LR in the solutions before and after exposure were measured, and the difference calculated to obtain the mass adsorbed.

Diffusive and binding gel preparation. The diffusive gel was made according to Zheng et al. ${ }^{29}$. Briefly, $0.15 \mathrm{~g}$ agarose was dissolved in $10 \mathrm{~mL}$ water and heated to $100^{\circ} \mathrm{C}$ to create a $1.5 \%$ agarose solution. The hot solution was injected into pre-warmed gel-casting molds, which includes two sheets of glass separated by $0.45 \mathrm{~mm}$ spacers (made of polyethyleneterephthalate). The solution was left to cool to room temperature. The gels were stored in $0.01 \mathrm{M} \mathrm{NaCl}$ solution, and were cut to the desired shape before use; the rounded cutting knife was made of Hadfield Steel. The binding gel was made by mixing $400 \mathrm{mg}$ of HLB in $10 \mathrm{~mL}$ of $1.5 \%$ warm agarose solution. The mixture was injected into preheated molds (two glass sheets separated by $0.45 \mathrm{~mm}$ thick spacers), then left to cool to room temperature. The binding gels were stored in ultrapure water and cut into disks before use. 
Binding kinetics and elution efficiency. The HLB binding gel disks were immersed and shaken in $20 \mathrm{~mL}$ of $200 \mu \mathrm{g} \mathrm{L}^{-1} \mathrm{MC}-\mathrm{LR}(0.01 \mathrm{M} \mathrm{NaCl}, \mathrm{pH}=7.0)$ for time intervals of $5 \mathrm{~min}, 10 \mathrm{~min}, 20 \mathrm{~min}, 30 \mathrm{~min}, 60 \mathrm{~min}, 90 \mathrm{~min}$, $120 \mathrm{~min}, 240 \mathrm{~min}$, and $480 \mathrm{~min}$. Four kinds of eluents were selected: A: $10 \mathrm{~mL}$ of methanol; B: $7 \mathrm{~mL}$ of metha$\mathrm{nol}+3 \mathrm{~mL}$ of $1 \mathrm{M} \mathrm{NaOH}$; $\mathrm{C}: 9 \mathrm{~mL}$ of methanol $+1 \mathrm{~mL}$ of $1 \mathrm{M} \mathrm{NaOH}$; and $\mathrm{D}: 7 \mathrm{~mL}$ of methanol $+3 \mathrm{~mL}$ of $1 \mathrm{M} \mathrm{HCl}$. The binding gels loaded with MC-LR were extracted for $24 \mathrm{~h}$ at $25^{\circ} \mathrm{C}$. The eluents were injected directly into the HPLC to obtain the elution efficiency.

Diffusion coefficient. The diffusion coefficient of MC-LR in the agarose gel was estimated during a DGT time-series deployment experiment. The HLB DGTs were deployed into $2 \mathrm{~L}$ mixed solutions containing $0.01 \mathrm{M}$ $\mathrm{NaCl}$ and $200 \mu \mathrm{g} \mathrm{L}^{-1} \mathrm{MC}-\mathrm{LR}(\mathrm{pH}=7)$ at $25^{\circ} \mathrm{C}$. The DGT devices were deployed and retrieved at several time intervals ranging from $4 \mathrm{~h}$ to $24 \mathrm{~h}$. The binding gels were rinsed with ultrapure water, then eluted and detected by the methods described above. The mass of MC-LR in the binding gel was calculated by Eq. (4):

$$
M=\frac{C_{e}\left(V_{g}+V_{e}\right)}{f_{e}}
$$

Where $C_{e}$ is the MC-LR concentration in the eluted solution, $V_{g}$ and $V_{e}$ are Volumes of the gel and eluent, respectively, and $f_{e}$ is the elution efficiency. The effective diffusion coefficient $\left(D, \mathrm{~cm}^{2} \mathrm{~s}^{-1}\right.$; Eq. (5)) was computed from the slope of the linear regression for M, from Eq. (4) as a function of the thickness of the diffusive layer $(\Delta g$, $0.60 \mathrm{~mm})$, the area of the diffusive window $\left(A, 3.14 \mathrm{~cm}^{2}\right)$, and the concentration of the solution $\left(C_{\text {soln }}, \mathrm{ng} \mathrm{mL}^{-1}\right)$.

$$
D=\frac{\text { slope } \cdot \Delta g}{C_{\text {sol }} \cdot A \cdot 60}
$$

The coefficient measured was specific to $25^{\circ} \mathrm{C}$; however, the effective diffusion coefficient at other temperatures can be corrected using Zhang's method $^{20}$.

Effects of $\mathrm{pH}$ and ionic strength, capacity. The effects of $\mathrm{pH}$ and ionic strength (IS) on the measurement of MC-LR by DGT methods were examined by deploying the DGT units in several $2 \mathrm{~L}$ (self-made, cylindrical), well-stirred (magnetic stirring apparatus), and mixed solutions containing $200 \mu \mathrm{g} \mathrm{L}-1$ of MC-LR at $25^{\circ} \mathrm{C}$ for $24 \mathrm{~h}$. To evaluate the effect of $\mathrm{pH}$, DGT devices were immersed in $2 \mathrm{~L}$ of well-stirred solutions $(0.01 \mathrm{M} \mathrm{NaCl})$ with $\mathrm{pH}$ of $5,6,7$, or 8 . To evaluate the effect of IS, DGT devices were immersed in $2 \mathrm{~L}$ of well-stirred solutions $(\mathrm{pH}=7)$ with IS of $0.001 \mathrm{M}, 0.01 \mathrm{M}, 0.1 \mathrm{M}$, or $0.5 \mathrm{M}$ using $\mathrm{NaCl}$.

To measure the capacity for accumulating MC-LR by HLB gels incorporated in DGT, the assembled DGT units were deployed in $2 \mathrm{~L}$ well-stirred solutions containing $200 \mu \mathrm{g} \mathrm{L}^{-1}$ of $\mathrm{MC}-\mathrm{LR}(\mathrm{pH}=7, \mathrm{IS}=0.01 \mathrm{M})$ using the time-series DGT accumulation experiments. The deployment times were $2 \mathrm{~h}, 4 \mathrm{~h}, 8 \mathrm{~h}, 12 \mathrm{~h}, 16 \mathrm{~h}, 24 \mathrm{~h}, 30 \mathrm{~h}, 36 \mathrm{~h}$, $48 \mathrm{~h}$, and $60 \mathrm{~h}$.

DGT blanks and method detection limits. To determine the blank of DGT devices for detecting MC-LR, six replicates of the blank DGT units were deployed into $2 \mathrm{~L}$ of $0.01 \mathrm{M} \mathrm{NaCl}$ solution for $24 \mathrm{~h}$. The concentrations of MC-LR in the blank gels were eluted using methanol (see Results and Discussion for the reason in choosing this eluent). The DGT concentrations were calculated by Eq. (1) using the following parameters: $24 \mathrm{~h}$ deployment time, $0.60 \mathrm{~mm}$ thickness of the diffusion layer and the DBL thickness, $3.14 \mathrm{~cm}^{2}$ exposure area, and the diffusion coefficient for MC-LR at $25^{\circ} \mathrm{C}$.

Application in natural waters. The DGT units were deployed at Meiliang Bay to calculate the DBL. The $\mathrm{pH}$, temperature and conductivity of water were measured in situ every day. Water samples were collected and tested every day. Three sets of DGT samplers with different diffusive layer thicknesses $(\Delta g=0.45 \mathrm{~mm}, 0.80 \mathrm{~mm}$, $1.00 \mathrm{~mm}$ ) with filter $(0.15 \mathrm{~mm})$ were deployed for 7 days to determine the DBL according to Warnken's ${ }^{41}$ method.

The HLB DGT devices were deployed in natural freshwater to evaluate the performance. Four DGT units were assembled leaving the exposure windows outward, then they were placed in Meiliang Bay within Taihu Lake (Jiangsu Province) for 4 days. Meiliang Bay is representative of a eutrophic zone, and is located in the northeast portion of Taihu Lake. The MC concentrations in Meiliang Bay have been detected monthly since 2007. The water temperature was measured every 4 hours. The grab samples of water $(1 \mathrm{~L})$ were collected at 10:00 am for 4 consecutive days.

The water samples were transferred to the laboratory within 30 minutes and the concentration of MC-LR was measured following Su et al. ${ }^{7}$ as described in section "Chemical Analysis". The HLB gels with MC-LR were immersed in $10 \mathrm{~mL}$ methanol for $24 \mathrm{~h}$. The final eluents from DGT measurements were filtered through a 0.45 $\mu \mathrm{m}$ membrane (aqueous phase) and transferred to $2 \mathrm{~mL}$ amber HPLC sample vials for instrument analysis. The accuracy and quality of the analysis was controlled by inserting standard samples (MC-LR $10 \mu \mathrm{gL}^{-1}$, in methanol) every 10 test samples.

\section{Conclusion}

A novel DGT device using HLB resin has been developed for detection of MC-LR in freshwater. The HLB gel was proved with high capacity and rapid binding kinetics for MC-LR. The DGT units with HLB binding gel was not affected by $\mathrm{pH}$ in the range of $5-8$ and ionic strength $(0.001 \mathrm{M}-0.5 \mathrm{M})$ values. In the field trial, the MC-LR was detected by the HLB-DGT devices and the results showed agreement with the active sampling method. The analysis results indicated that the HLB-DGT probe coupled with HPLC had the benefits of preconcentration and high sensitivity. This novel method was confirmed to be a potentially valuable and powerful tool for measuring trace MC-LR in freshwater and can extend to other environmental matrix. 
Received: 25 April 2019; Accepted: 31 October 2019; Published online: 26 November 2019

\section{References}

1. Buratti, F. M. et al. Cyanotoxins: producing organisms, occurrence, toxicity, mechanism of action and human health toxicological risk evaluation. Arch. Toxicol. 91, 1049-1130, https://doi.org/10.1007/s00204-016-1913-6 (2017).

2. Chen, L., Chen, J., Zhang, X. \& Xie, P. A review of reproductive toxicity of microcystins. J. Hazard. Mater. 301, 381-399, https://doi. org/10.1016/j.jhazmat.2015.08.041 (2016).

3. Harke, M. J. et al. A review of the global ecology, genomics, and biogeography of the toxic cyanobacterium, Microcystis spp. Harmful Algae 54, 4-20, https://doi.org/10.1016/j.hal.2015.12.007 (2016).

4. Li, J., Li, R. \& Li, J. Current research scenario for microcystins biodegradation - A review on fundamental knowledge, application prospects and challenges. Sci. Total Environ. 595, 615-632, https://doi.org/10.1016/j.scitotenv.2017.03.285 (2017).

5. Falconer, I. R., Burch, M. D., Steffensen, D. A., Choice, M. \& Coverdale, O. R. Toxicity of the blue-green alga (cyanobacterium) Microcystis aeruginosa in drinking water to growing pigs, as an animal model for human injury and risk assessment. Environ. Toxicol. Water Qual. 9, 131-139, https://doi.org/10.1002/tox.2530090209 (1994).

6. Niu, W. et al. Use of fluorescent europium chelates as labels for detection of microcystin-LR in Taihu Lake, China. J. Rare Earths 30, 941-946, https://doi.org/10.1016/s1002-0721(12)60158-6 (2012).

7. Su, X., Xue, Q., Steinman, D. A., Zhao, Y. \& Xie, L. Spatiotemporal dynamics of microcystin variants and relationships with environmental parameters in Lake Taihu, China. Toxins 7, 3224-3244, https://doi.org/10.3390/toxins7083224 (2015).

8. Liu, Y. et al. Cyanobacteria-/cyanotoxin-contaminations and eutrophication status before wuxi drinking water crisis in Lake Taihu, China. J. Environ. Sci. 23, 575-581, https://doi.org/10.1016/s1001-0742(10)60450-0 (2011).

9. Zhang, D., Xie, P., Liu, Y., Chen, J. \& Wen, Z. Spatial and temporal variations of microcystins in hepatopancreas of a freshwater snail from Lake Taihu. Ecotoxicol. Environ. Saf. 72, 466-472, https://doi.org/10.1016/j.ecoenv.2008.05.014 (2009).

10. Massey, I. Y. et al. Exposure routes and health effects of microcystins on animals and humans: a mini-review. Toxicon 151, 156-162, https://doi.org/10.1016/j.toxicon.2018.07.010 (2018).

11. Sun, X. et al. Longitudinal surface plasmon resonance assay enhanced by magnetosomes for simultaneous detection of Pefloxacin and Microcystin-LR in seafoods. Biosens. Bioelectron. 47, 318-323, https://doi.org/10.1016/j.bios.2013.03.046 (2013).

12. Cheng, H. et al. Parental exposure to microcystin-LR induced thyroid endocrine disruption in zebrafish offspring, a transgenerational toxicity. Environ. Pollut. 230, 981-988, https://doi.org/10.1016/j.envpol.2017.07.061 (2017).

13. Chorus, I. \& Bartram, J. Toxic cyanobacteria in water:a guide to public health consequences, monitoring and management. 416 (E \& FN Spon on behalf of the World Health Organization, 1999).

14. Li, C. et al. Transformation of bisphenol A in water distribution systems: A pilot-scale study. Chemosphere 125, 86-93, https://doi. org/10.1016/j.chemosphere.2014.11.047 (2015).

15. Meng, F., Wen, D. \& Sloan, J. Modelling of air-water exchange of PCBs in the Great Lakes. Atmos. Environ. 42, 4822-4835, https:// doi.org/10.1016/j.atmosenv.2008.02.050 (2008).

16. Gong, X. et al. Passive sampling for monitoring polar organic pollutants in water by three typical samplers[J]. Trends in Environmental Analytical Chemistry 17, 23-33, https://doi.org/10.1016/j.teac.2018.01.002 (2018).

17. Morin, N., Miège, C., Coquery, M. \& Randon, J. Chemical calibration, performance, validation and applications of the polar organic chemical integrative sampler (POCIS) in aquatic environments. Trends Anal. Chem. 36, 144-175, https://doi.org/10.1016/j. trac.2012.01.007 (2012).

18. Greenwood, R. et al. Chapter 9 monitoring of priority pollutants in water using chemcatcher passive sampling devices. Compr. Anal. Chem. 48, 199-229, https://doi.org/10.1016/S0166-526X(06)48009-0 (2007).

19. Kudela, R. M. Characterization and deployment of Solid Phase Adsorption Toxin Tracking (SPATT) resin for monitoring of microcystins in fresh and saltwater. Harmful Algae 11, 117-125, https://doi.org/10.1016/j.hal.2011.08.006 (2011).

20. Zhang, H. \& Davison, W. Performance characteristics of diffusion gradients in thin films for the in situ measurement of trace metals in aqueous solution. Anal. Chem. 67, 3391-3400, https://doi.org/10.1021/ac00115a005 (1995).

21. Kohoutek, J., Babica, P., Bláha, L. \& Maršálek, B. A novel approach for monitoring of cyanobacterial toxins: development and evaluation of the passive sampler for microcystins. Anal. Bioanal. Chem. 390, 1167-1172, https://doi.org/10.1007/s00216-0071785 -y (2008).

22. Kohoutek, J., Maršálek, B. \& Bláha, L. Evaluation of the novel passive sampler for cyanobacterial toxins microcystins under various conditions including field sampling. Anal. Bioanal. Chem. 397, 823-828, https://doi.org/10.1007/s00216-010-3578-y (2010).

23. Miller, M. A. et al. Evidence for a novel marine harmful algal bloom: cyanotoxin (microcystin) transfer from land to sea otters. PLoS One 5, e12576, https://doi.org/10.1371/journal.pone.0012576 (2010).

24. Vrana, B. et al. Passive sampling techniques for monitoring pollutants in water. Trends Anal. Chem. 24, 845-868, https://doi. org/10.1016/j.trac.2005.06.006 (2005)

25. Roué, M., Darius, H. T. \& Chinain, M. Solid Phase Adsorption Toxin Tracking (SPATT) technology for the monitoring of aquatic toxins: areview. Toxins 10, 167, https://doi.org/10.3390/toxins10040167 (2018).

26. Davison, W. \& Zhang, H. In situspeciation measurements of trace components in natural waters using thin-film gels. Nature 367, 546-548, https://doi.org/10.1038/367546a0 (1994).

27. Chen, C. E. et al. Evidence and Recommendations to Support the Use of a Novel Passive Water Sampler to Quantify Antibiotics in Wastewaters[J]. Environmental Science \& Technology 47(23), 13587-13593, https://doi.org/10.1021/es402662g (2013).

28. Chen, C. E., Zhang, H. \& Jones, K. C. A novel passive water sampler for in situ sampling of antibiotics. J. Environ. Monit. 14, 1523-1530, https://doi.org/10.1039/c2em30091e (2012).

29. Zheng, J. et al. Activated charcoal based diffusive gradients in thin-films for in situ monitoring of bisphenols in waters. Anal. Chem. 87, 801-807, https://doi.org/10.1021/ac503814j (2015).

30. Chen, W. et al. DGT passive sampling for quantitative in situ measurements of compounds from household and personal care products in waters. Environ. Sci. Technol. 51, 13274-13281, https://doi.org/10.1021/acs.est.7b03940 (2017).

31. Zou, Y. T. et al. Novel method for in situ monitoring of organophosphorus flame retardants in waters. Anal. Chem. 90, 10016-10023 (2018).

32. Xie, L. \& Park, H. D. Determination of microcystins in fish tissues using HPLC with a rapid and efficient solid phase extraction. Aquaculture 271, 530-536, https://doi.org/10.1016/j.aquaculture.2007.07.004 (2007).

33. Scally, S., Davison, W. \& Zhang, H. Diffusion coefficients of metals and metal complexes in hydrogels used in diffusive gradients in thin films. Anal. Chim. Acta 558, 222-229, https://doi.org/10.1016/j.aca.2005.11.020 (2006).

34. Luo, J., Zhang, H., Santner, J. \& Davison, W. Performance characteristics of diffusive gradients in thin films equipped with a binding gel layer containing precipitated ferrihydrite for measuring arsenic (V), selenium (VI), vanadium (V), and antimony (V). Anal. Chem. 82, 8903-8909, https://doi.org/10.1021/ac101676w (2010).

35. Kim, S., Yun, Y. S. \& Choi, Y. E. Development of waste biomass based sorbent for removal of cyanotoxinmicrocystin-LR from aqueous phases. Bioresour. Technol. 247, 690-696 (2018).

36. Jeong, Y., Schäffer, A. \& Smith, K. Equilibrium partitioning of organic compounds to OASIS HLB ${ }^{\circledR}$ as a function of compound concentration, $\mathrm{pH}$, temperature and salinity. Chemosphere 174, 297-305, https://doi.org/10.1016/j.chemosphere.2017.01.116 (2017). 
37. TerLaak, T. L., Gebbink, W. A. \& Tolls, J. The effect of $\mathrm{pH}$ and ionic strength on the sorption of sulfachloropyridazine, tylosin, and oxytetracycline to soil. Environ. Toxicol. Chem. 25, 904-911, https://doi.org/10.1897/05-232r.1 (2010).

38. Zhang, Z., Hibberd, A. \& Zhou, J. L. Analysis of emerging contaminants in sewage effluent and river water: comparison between spot and passive sampling. Anal. Chim. Acta 607, 37-44, https://doi.org/10.1016/j.aca.2007.11.024 (2008).

39. Togola, A. \& Budzinski, H. Development of polar organic integrative samplers for analysis of pharmaceuticals in aquatic systems. Anal. Chem. 79, 6734-6741, https://doi.org/10.1021/ac070559i (2007).

40. Xie, H. et al. Development and evaluation of diffusive gradients in thin films technique for measuring antibiotics in seawater[J]. Science of The Total Environment 618, 1605-1612, https://doi.org/10.1016/j.scitotenv.2017.09.330 (2017).

41. Warnken, K. W., Zhang, H. \& Davison, W. Accuracy of the diffusive gradients in thin-films technique: diffusive boundary layer and effective sampling area considerations. Analytical chemistry 78(11), 3780-3787, https://doi.org/10.1021/ac060139d (2006).

42. Hotto, A. M., Satchwell, M. F., Berry, D. L., Gobler, C. J. \& Boyer, G. L. Spatial and temporal diversity of microcystins and microcystin-producing genotypes in oneida lake, NY. Harmful Algae 7, 671-681, https://doi.org/10.1016/j.hal.2008.02.001 (2008).

\section{Acknowledgements}

This research was supported by National Natural Science Foundation of China "Grant No. 41877486", National water pollution control and management technology major projects (2018ZX07208008) and Science and Technology Service Network Initiative (KFJ-STS-ZDTP-038-3).

\section{Author contributions}

L.Y. wrote the main manuscript text. L.Y., A.D.S., X.W., X.S. and L.X. designed and conducted the experiments and collected and analyzed the data. A.D.S. and L.X. checked and modified the manuscript text.

\section{Competing interests}

The authors declare no competing interests.

\section{Additional information}

Correspondence and requests for materials should be addressed to L.X.

Reprints and permissions information is available at www.nature.com/reprints.

Publisher's note Springer Nature remains neutral with regard to jurisdictional claims in published maps and institutional affiliations.

(c) (i) Open Access This article is licensed under a Creative Commons Attribution 4.0 International License, which permits use, sharing, adaptation, distribution and reproduction in any medium or format, as long as you give appropriate credit to the original author(s) and the source, provide a link to the Creative Commons license, and indicate if changes were made. The images or other third party material in this article are included in the article's Creative Commons license, unless indicated otherwise in a credit line to the material. If material is not included in the article's Creative Commons license and your intended use is not permitted by statutory regulation or exceeds the permitted use, you will need to obtain permission directly from the copyright holder. To view a copy of this license, visit http://creativecommons.org/licenses/by/4.0/.

(c) The Author(s) 2019 